Referencia para citar este artículo: Castaño-Ravagli, M. \& Álvarez-Giraldo, C. M. (2017). El trabajo: concepciones de jóvenes que laboran en Call Centers en una ciudad intermedia colombiana. Revista Latinoamericana de Ciencias Sociales, Niñez y Juventud, 15 (2), pp. 1223-1236. DOI:10.11600/1692715x.1522929072016

\title{
El trabajo: concepciones de jóvenes que laboran en Call Centers en una ciudad intermedia colombiana*
}

\author{
MARIANA CASTAÑO-RAVAGLI ${ }^{\text {** }}$ \\ Joven investigadora Colciencias Universidad de Manizales, Colombia.
}

ClaUdia MILENA ÁlVAREZ-GIRALDo ${ }^{* * *}$

Profesora Universidad Nacional de Colombia, Colombia.

\section{Artículo recibido en julio 29 de 2016; artículo aceptado en octubre 3 de 2016 (eds.)}

- Resumen (descriptivo): las organizaciones actuales han desarrollado nuevos modelos para almacenar, transferir y transformar la información; esta era se caracteriza por su alta demanda de las nuevas tecnologías y de las características del individuo trabajador, lo que ha favorecido el desarrollo de la industria Business Process Outsourcing $\left(B P O^{1}\right)$, logrando atraer a nuevos trabajadores y trabajadoras jóvenes. Sin embargo, aunque se han mejorado las condiciones de empleabilidad, pareciera que su dinámica cambia tangencialmente las consideraciones sobre el trabajo. En tal sentido, en el presente artículo intento comprender los imaginarios y subjetividades del concepto de "trabajo", asumido por los sujetos jóvenes trabajadores en este tipo de organizaciones de la ciudad de Manizales. Metodológicamente, el estudio lo llevé a cabo desde una perspectiva hermenéutica mediante la aplicación de entrevistas a profundidad a las personas jóvenes, para conocer su postura y comprender la relación ser humano-trabajo. Presento los resultados desde los imaginarios, representaciones, sentido y concepción de los jóvenes y las jóvenes frente al trabajo y sus percepciones de calidad de vida, lo cual en términos generales refleja su adaptación y aceptación de las condiciones actuales de flexibilidad laboral en el país -particularmente en la región-, y la vulnerabilidad en que se encuentran. Como futuras líneas de investigación y desde algunos vacíos evidenciados, planteo la necesidad de abordar el estudio desde otras perspectivas metodológicas que permitan dar explicaciones acerca de la aceptación acrítica de las gentes jóvenes sobre las características del trabajo actual y su aporte a la construcción de nuevas prácticas laborales, al igual que indagar sobre las nuevas identidades de los individuos jóvenes.

Este artículo de investigación científica y tecnológica hace parte del proyecto denominado "Imaginarios y subjetividades del trabajo en jóvenes: condiciones para la construcción de ciudadanía" el cual hace parte del programa "Sentidos y prácticas políticas de niños, niñas y jóvenes en contextos de vulnerabilidad en el eje cafetero, Antioquia y Bogotá: un camino posible de consolidación de la democracia, la paz y la reconciliación mediante procesos de formación ciudadana" realizado entre diciembre del 2014 y julio de 2016 (Código de proyecto en el sistema de investigaciones de Universidad de Manizales: B0601X0303) Área: sociología; subárea: temas sociales.

** Joven investigadora Colciencias- Colombia - Universidad de Manizales; Magister en Gerencia del Talento Humano, Especialista en Gerencia del Talento Humano, Comunicadora social y periodista, Universidad de Manizales. Investigadora grupo de investigación Administración y Gerencia del Talento Humano Categoría A1 Colciencias. Orcid: 0000-0001-7817-1051. Correo electrónico: mcastano@umanizales.edu.co.

*** Candidata a doctor en Dirección de Empresas, Magister en Gerencia del Talento Humano, Administradora de empresas, Investigadora Senior Colciencias, profesora asociada, Coordinadora grupo de investigación Administración y Gerencia del Talento Humano Categoría A1 Colciencias, Universidad de Manizales, profesora asociada Universidad Nacional de Colombia sede Manizales. Orcid: 0000-0002-6366-4301. Índice H5: 10. Correo electrónico: calvarez@umanizales.edu.co; cmalvarezg@unal.edu.co

1 Los servicios BPO se refieren a la subcontratación de funciones de procesos de negocio con proveedores de servicios, ya sea internos o externos a la compañía" (CPC, 2010). 
Palabras clave: BT: juventud, RT: oportunidades de empleo, NT: participación de los jóvenes, MT: 450 colectivo laboral, USE: relaciones laborales, RT: mundo del trabajo (Tesauro de Ciencias Sociales de la Unesco).

\section{Work: Conceptions of young people working in call centers in a middle-sized Colombian city}

- Abstract (descriptive): today's organizations have developed new models to store, transfer and transform information, which is characterized by a high demand for new technologies and related skills in workers, which has favored the development of the Business Process Outsourcing (BPO) industry. These jobs attract new and young workers, and although there are improved employment conditions, it seems that the dynamic of this industry changes how people see the notion of work. In this regard, some youth perceptions are presented against the concept of work, the sense that this population gives to their work and the conditions they perceive. Methodologically, the research was conducted used a hermeneutical perspective by conducting in-depth interviews with young people to identify their perceptions regarding work and to understand the human being-work relationship.

Key words: BT: youth, RT: employment opportunities, NT: youth participation, MT: 450 work collective, USE: labor relations, RT: world of work, RT: youth opportunities (Unesco Social Sciences Thesaurus).

\section{Trabalho: Concepções de jovens que trabalham em call centers em uma cidade de tamanho médio colombiana}

- Resumo (descritivo): as organizações de hoje têm desenvolvido novos modelos para armazenar, transferir e transformar a informação, esta nova era é caracterizada pela alta demanda por novas tecnologias e características do trabalhador, o que tem favorecido o desenvolvimento de indústrias de Business Process Outsourcing (BPO), conseguindo atrair novos jovens trabalhadores, no entanto, mesmo que as condições de empregabilidade tenham melhorado, parece que sua dinâmica altera tangencilmente as considerações deste trabalho. Neste sentido o presente artigo tenta compreender os imaginários e subjetividades do conceito de trabalho algumas percepções dos jovens sobre o trabalho assumido por jovens que trabalham com este tipo de organizações na cidade de Manizales. Metodologicamente, o estudo foi realizado a partir de uma perspectiva hermenêutica através da aplicação de entrevistas em profundidade com os jovens para encontrar a sua posição e compreender relação homem-trabalho. Os resultados apresentam-se desde os imaginários, representações, sentido e concepção dos jovens frente ao trabalho e suas percepções de qualidade de vida, a qual em termos gerais refletem sua adaptação e aceitação laboral no país, região e vulnerabilidade em que se encontram. Como futuras linhas de investigação e alguns espaços vazios evidenciados, se plantea a necessidade de abordar o estudo desde outras perspectivas metodológicas que permitam dar explicações acerca da aceitação crítica dos jovens sobre as características do trabalho atual e seu aporte a construção de novas práticas laborais semelhante as novas identidades dos jovens.

Palavras-chave: BT: juventude, RT: oportunidades de emprego, NT: participação juvenil, MT: 450 trabalho coletivo, USE: relações de trabalho, RT: mundo do trabalho, RT: oportunidades para a juventude (Thesaurus de Ciências Sociais da Unesco).

-1. Introducción. -2. Concepciones de trabajo: una mirada desde la literatura en contraste con la percepción de jóvenes. -3. Consideraciones metodológicas. -4. Resultados. -5. Conclusiones. -Lista de referencias. 


\section{Introducción}

La problemática que actualmente viven los individuos jóvenes colombianos se da no solo por el contexto de violencia y de bajo dinamismo económico en el que se encuentran, sino también por la falta de oportunidades en el ámbito laboral y por los altos porcentajes de desempleo en la ciudad, y en general el país.

Colombia tiene una tasa de desempleo juvenil para el último trimestre de 2014 del 14,3\%; específicamente en Manizales, según la Gran Encuesta Integrada de Hogares del Dane (2015), el desempleo en los individuos jóvenes de edades entre 14 y 28 años para el año 2014 , era de $17,7 \%$, lo que representa una débil integración social, política y territorial, generando a su vez una gran diversidad de conflictos de origen cultural, étnico, clasista y regional. Lo anterior es un gran desafío para la ciudad, pues es la tasa de desempleo juvenil la que indica el gran problema que tiene el empleo y los sistemas de trabajo, no sólo en el país sino en general en el mundo.

En el Eje Cafetero, y más concretamente en la ciudad de Manizales, se ha visto un crecimiento importante de los call center, caracterizados por la flexibilización del trabajo y el manejo de las tecnologías de información y comunicación (TIC). Esta nueva modalidad de trabajo atrae constantemente a la población más joven, que tiene una gran habilidad para el manejo operativo de las nuevas tecnologías. "En muchos países de América Latina, el sector de los servicios absorbe entre ocho y nueve de cada diez trabajadores jóvenes y el resto trabaja en el sector de las manufacturas o la construcción" (Organización Internacional del Trabajo, 2004). Sin embargo, también se percibe una pérdida de la identidad social de esta colectividad que se encuentra excluida, donde los jóvenes pierden la esperanza de obtener algo mejor y se quedan satisfechos pensando que es el mejor trabajo al que pueden aspirar por su falta de experiencia en otras actividades:

El $97 \%$ de los trabajadores menores de 30 años no han tenido un trabajo distinto al que desempeñan actualmente en el call center y para el total de empleados se nota que casi el $60 \%$ de su vida laboral formal es en este tipo de servicios. En ese sentido, el sector genera empleos para los jóvenes y les permite tener experiencia en el mundo del trabajo, siendo una buena estrategia de enganche laboral para los jóvenes con pocas competencias laborales desde su formación y experiencia de trabajo (Castro \& Soto, 2012, p. 16).

En Colombia, el principal factor que rige el ingreso de la población joven al mercado laboral es la circunstancia socioeconómica de su familia; los sujetos jóvenes marcados por la precariedad y la exclusión suelen ser más propensos a encontrar trabajo informal; de igual forma, la falta de dinero, la oferta institucional -privada-pública- con sus altos costos educativos, la deserción escolar, la baja calidad en la educación y la obligación en el hogar, determinan el futuro de las personas jóvenes en empleos precarios y de mala calidad. Las urgencias económicas obligan a que el joven o la joven, desde muy temprana edad, se involucre en procesos de plena adultez (Valenzuela, 1998).

Es de interés indagar sobre los aspectos que intervienen en la crisis laboral que enfrenta el departamento de Caldas, ya que para el año 2015 , el $17.4 \%$ de las personas ocupadas no estaban satisfechas con su trabajo (Dane, 2015), cifra que está acompañada de las tasas de desempleo, inclusión y exclusión de los individuos jóvenes, quienes se encuentran ante un entorno económico difícil y son más propensos a encontrar empleos precarios $\mathrm{y}$ desfavorables, tanto para su desarrollo personal, como profesional. Entre diciembre del 2015 y febrero del 2016, el desempleo se ubicó en el $10,7 \%$, lo que representa que hay $23 \mathrm{mil}$ desempleados, mil más que el mismo trimestre del año pasado, cuando la cifra estaba en $10,1 \%$. (Cardona, 2016). A su vez, según la Fuente de Información Laboral de Colombia (Filco), en el año 2015 el número de subempleados subjetivos representaba un $39,5 \%$, lo que demuestra los altos niveles de inconformidad respecto a las condiciones de empleabilidad del país. ${ }^{22}$

22 Fuente de información laboral -Filco-. Recuperada de: http://filco.mintrabajo.gov.co/pages/detalleIndicador. xhtml?idIndicador $=104$ 
Lo anterior representa la metamorfosis que ha tenido el mundo laboral contemporáneo. Ha cambiado radicalmente la manera de trabajar, el modelo posfordista ha modificado las relaciones de producción, distribución y consumo a nivel mundial, con la entrada de las multinacionales y de las transnacionales, y se han intensificado la precarización laboral, la incertidumbre y el riesgo en los trabajadores y trabajadoras, en palabras de Blanch (2011). El nuevo (des)orden laboral posmoderno y posfordista da lugar a un mundo complejo y dinámico, donde se combinan y confunden, según países y épocas, diversos tipos y tasas de empleo, subempleo y desempleo, y formas más o menos residuales de trabajo servil, sumergido e informal. Las personas jóvenes en Colombia representan un alto porcentaje de fuerza laboral, con un estimado de más de doce millones de ciudadanos y ciudadanas entre los 14 y los 28 años de edad; sin embargo, según el Dane, durante el primer trimestre de 2015 el 16\% de esta población se encontraba desempleada (Portafolio, 2015).

De acuerdo con el informe Nacional de Competitividad 2014-2015, el desafío para el año 2015 fue de gran magnitud, pues para ese año 660 millones de jóvenes estaban trabajando o buscando trabajo, lo que representó un aumento del 7,5\% con respecto al número de jóvenes que formaban parte de la población activa en 2003; además, durante el decenio que finalizó en 2015, hubo más personas que buscaban trabajo por primera vez que en ningún otro momento de la historia.

Desde los años 60, los jóvenes y las jóvenes son la mitad de desempleados y subempleados en Colombia; sin embargo, con la elevada concentración en la rama del sector de los servicios y el desarrollo de varios programas que buscan mejorar su empleabilidad, diseñar, gestionar y evaluar la oferta, etc., no hay un indicador de impacto que permita determinar si ha existido un beneficio para esta población. El 85\% de nuevas oportunidades en el país se presenta en la economía informal, y quienes se ven más afectados por ello son los individuos jóvenes que se encuentran en situaciones económicas desfavorables, ya que no tienen muchas alternativas laborales pero sí cargan con la necesidad de generar ingresos a causa de su contexto familiar, caracterizado porque viven en zonas de la ciudad donde la pobreza es más latente. Esto se debe a que son poblaciones de menor estrato socioeconómico, lo que se relaciona con las dotaciones educativas, las cuales se concentran sobre todo en la formación secundaria completa y en ciclos de formación técnica. Pensar en una agenda de inclusión laboral no es posible, primero porque no se realizan ajustes en la calidad de la educación de los sujetos jóvenes, ya que muchos de ellos no pueden acceder a un empleo formal por la falta de conocimientos y de experiencia, y porque el analfabetismo tecnológico es una de las barreras de acceso al mercado de los call center.

No obstante, a pesar de las diferencias socioculturales y socioeconómicas de las regiones y de los países, hay algo en lo que hay coincidencias: millones de personas sin acceso a un empleo formal, millones de personas sin derecho a prestaciones, millones de personas sin acceso a educación media o superior y millones de personas sin acceso o sin derecho a un futuro mejor (Rivera-González, 2011). El nuevo mundo del trabajo está permeado por políticas neoliberales, especialmente Colombia donde emergen nuevas formas de exclusión y vulnerabilidad social, aumentando en gran medida las condiciones de desigualdad y pobreza en el país y afectando más que todo a la población juvenil.

Si Colombia aspira a ser en el año 2032 la economía más competitiva de América Latina, deberá generar en el año 2018 1,5 millones de nuevos empleos (Consejo Privado de Competitividad, 2010). Para lograr tan anhelado objetivo se debe eliminar la pobreza mediante la generación de trabajo decente para los jóvenes y las jóvenes, teniendo en cuenta la gran mayoría de individuos jóvenes que no logra obtener un empleo por no tener el conocimiento necesario, o simplemente porque no tienen los recursos para acceder a una educación de buena calidad. Por lo anterior, los jóvenes y las jóvenes no logran encontrar un empleo acorde con sus gustos y necesidades; es entonces que el gobierno nacional y las administraciones locales deben poner en marcha acciones de política y planeación económica que logren 
reducir la brecha laboral entre hombres y mujeres, y que reduzcan el desempleo juvenil, teniendo en cuenta que para el año 2011 el $86 \%$ de los individuos jóvenes manifestó estar insatisfecho con las políticas de empleo, y el mismo porcentaje se mostró descontento con las oportunidades de empleo de la ciudad donde vive; además, el $72 \%$ expresó insatisfacción con la calidad de los empleos ofertados por el mercado de trabajo de su ciudad, y el $89 \%$ manifestó insatisfacción con la situación económica del país (Rojas, 2011).

\section{Concepciones de trabajo: una mirada desde la literatura en contraste con la percepción de la población joven}

Desde una perspectiva institucionalista, se asume al ser humano como el eje orientador y fundamental para establecer relaciones de confianza y legitimidad social, lo que es la base para la indagación sobre la construcción del concepto calidad de vida de los individuos jóvenes en colectivo. La teoría institucional parte del valor per se de las organizaciones, y trata de explicar qué determina la institucionalización de una acción o estructura y cuáles son las consecuencias de esa institucionalización sobre el comportamiento organizacional (Pfeffer, 1987). Algunos de los principales aportes de la teoría institucional son: la visión diferente de concebir el entorno y la construcción mediante la interacción social de esas relaciones entornoempresa; ir más allá de mirar la organización como sistema técnico y entender los sistemas simbólicos y culturales que existen en ella; y la visión holista de la organización y la valoración intrínseca de las organizaciones que lleva a la teoría a la búsqueda de explicaciones para su estabilidad y permanencia (Calderón, 2005).

Desde las teorías clásicas, el trabajo se ha pensado en términos de explotación: con el

(...) liberalismo económico el trabajo adquiere la condición de factor productivo y posteriormente bajo la perspectiva neoclásica de la economía, el trabajo se convierte en una mercancía cuyo precio es el salario, el que, dada su importancia en el naciente modelo productivo, se constituye en un costo que debe reducirse para poder aumentar la productividad industrial (Neffa, 2003).

La mayoría de los ciudadanos y ciudadanas trabaja para ser explotados; lo único que tienen es la fuerza de trabajo para poder venderla, y pocos sobreviven si no venden su fuerza de trabajo, salvo quien sea dueño de los medios de producción y que viva de la renta del capital. Para pensar en la realidad de las relaciones de los individuos jóvenes en el trabajo, hay que tener presente el contexto frívolo en el que se desenvuelven, porque ello debe significar mucho en la manera como se vive el hecho de ser joven; debe implicar algo para esta generación en la que se vive una gran incertidumbre social, donde se vende el trabajo bajo condiciones de tiempo menos estables y con relaciones humanas efímeras; allí donde el trabajo no genera más que inseguridad, informalidad y precariedad, pues para el año 2012 -según la Organización Internacional de TrabajoColombia era el país con la tasa de desempleo urbano juvenil más alta en América Latina, con el $24 \%$ de esta población en estado improductivo -desempleados e inactivos académicamente-, situación que lleva a la exclusión social derivada de las condiciones de trabajo, donde para este mismo -según la OIT- "los jóvenes de América Latina y el Caribe enfrentaban un problema de desempleo más elevado que el del resto de la población y, además, entre quienes logran una ocupación, ésta suele tener mayor precariedad laboral que la del promedio de la fuerza de trabajo" (Organización Internacional del Trabajo, 2012, p. 49).

Si bien la categoría trabajo puede haber perdido significación y la situación laboral es precaria, socialmente el concepto continúa siendo relevante no solo para el sustento sino como medio de inclusión social, y ha implicado que organismos internacionales, como la Organización Internacional del Trabajo, propongan el trabajo decente como un objetivo social de la época; lo anterior implica "crear un trabajo productivo en condiciones de libertad, equidad, seguridad y dignidad, en el cual los derechos son respetados, hay una remuneración adecuada y una buena protección social" (Somavía, 2000). En el año 2010 Colombia 
creó la ley 1429, más conocida como la ley del "Primer Empleo", la cual está centrada en formalizar y generar empleo a la población; esta ley tiene un marco para los sujetos jóvenes que busca mejorar su empleabilidad, diseñar, gestionar y evaluar la oferta, otorgar condiciones de garantía a empresas creadas por la gente joven menor de 28 años y, por último, dar incentivos a empresarios y empleadores que vinculen laboralmente a nuevos empleados y empleadas menores de 28 años. Sin embargo, a pesar de que han pasado diez años del nacimiento de la ley, no hay un indicador de impacto que permita determinar si ha existido un beneficio para la población joven.

Para comprender el significado que dan los jóvenes y las jóvenes al concepto de trabajo, es necesario comprender lo que sucede con las características socio demográficas de los individuos trabajadores de Manizales; específicamente hay una concentración del empleo en población joven; también es de resaltar que dichos sujetos jóvenes se encuentran en un entorno de bajo dinamismo económico, lo que se hace evidente ya que frente a sus condiciones de vida se determinó que la mayoría de los trabajadores y trabajadoras de call center viven en algunas comunas de la ciudad con mayor presencia de pobreza, las cuales registran una cifra inferior al promedio de Índice de Condiciones de Vida (ICV) de la ciudad; además, los niveles de ingreso del hogar también son inferiores y la presencia de pobreza subjetiva es algo importante (Cardona, Soto, Serna, Castro, Celis \& Botero, 2013).

En esta investigación se resuelve acuñar el término imaginario social, dado por el filósofo-psicoanalista Cornelius Castoriadis, desde el cual se representa la concepción de figuras/formas/imágenes de aquello que los sujetos llamamos "realidad", sentido común o racionalidad en una sociedad. Es allí donde el imaginario, una vez es compartido por varias personas, adquiere sentido, permitiendo el intercambio de contenidos y logrando comunicación entre sujetos de una misma situación económica, social y política que hacen de sus imaginarios 'su realidad', sin la posibilidad de transformar el mundo que los rodea; según Castoriadis (2009), esta realidad es construida, interpretada, leída por cada sujeto en un momento histórico social determinado.

Ese orden de sentido que da el imaginario social a la vida de las personas jóvenes en cuestiones laborales, constituye significaciones colectivas que al ser reproducidas se van transformando. Un individuo joven que piensa que su condición económica no le permite mayores oportunidades, hará que su realidad afecte de manera directa su situación, lo que contribuye a que cada sujeto defina su propia identidad y su posición en la comunidad dependiendo de su condición, y a que, según las características de éste, podrá participar en la vida productiva de una sociedad, tener ingresos, mejorar su autoestima y su perspectiva de realización personal, adquirir prestigio social y facilitar su participación cívica y política en la sociedad (Martínez, 2006).

Entiendo entonces como imaginario social aquellas ideas y pensamientos que son instituidos, aceptados y legitimados socialmente en un colectivo; dichos imaginarios dan cuenta de la mirada de la gente joven respecto a una categoría específica, con la intención de recuperar sus percepciones, percibirlas, valorarlas y resignificarlas mediante sus voces, sus comportamientos, sus deseos y su memoria. Sin embargo, también se tiene en cuenta que las características particulares de este concepto varían según el contexto en el que se ubique al ser humano, ya que cada uno tiene la posibilidad de tomar pedazos de la realidad y forjar sueños, ideas e imágenes que luego se construyen y aparecen como objetos, conceptos, formas o comportamientos "nuevos" en el mundo externo, que se asumen como una realidad dinámica y móvil, con diferentes formas de ver y sentir el mundo.

Es el imaginario el que permite saber cómo se ven las personas jóvenes y el papel que deben desempeñar en la sociedad. La creación que cada sujeto joven haga de su contexto va a transformar la idea que tiene de sí mismo y su rol en la sociedad. Desde una perspectiva sociodemográfica y según estudios del Dane, los individuos jóvenes que viven en estratos uno (bajo-bajo) y dos (bajo), corresponden a familias con escasos recursos y a su vez son beneficiarios de subsidios en los servicios públicos 
domiciliarios. Dichos individuos jóvenes, que trabajan en call center, tienen una noción poco favorable del trabajo que desempeñan. Según un estudio realizado sobre la calidad del empleo y las condiciones de trabajo en los call center en la ciudad de Manizales, los sujetos jóvenes están menos satisfechos con las actividades de rutina, con los espacios de descanso, con el reconocimiento social del trabajo y con otras condiciones (Castro \& Soto, 2012; Cardona et al., 2013).

Desde esta perspectiva, para comprender el imaginario se debe tener en cuenta la cultura en la cual se encuentra inmersa la vida de las personas por las cuales se indaga, y allí buscar mundos, comprender por qué trabajan, para qué lo hacen y cuáles son las prácticas que han asumido en este nuevo siglo inmerso en un mundo de lenguajes y de instituciones. Todo lo que encontramos de social en un individuo, es socialmente fabricado o creado, en correspondencia con las instituciones de la sociedad (Castoriadis, 1989); de ahí la importancia que éstas juegan en el comportamiento de los sujetos, tanto dentro como fuera de la organización.

Igualmente se debe tener en cuenta el rol de los líderes y lideresas en la organización, ya que juegan un papel fundamental en el imaginario que tiene la población joven frente a su trabajo, porque en gran medida son ellos y ellas quienes les inculcan pensamientos sobre su trabajo, los motivan a seguir y velan porque el ambiente laboral sea bueno y sus colaboradores y colaboradoras tengan una buena experiencia en su puesto de trabajo.

Nuevamente se observa cómo mediante el institucionalismo los individuos reconocen una definición compartida de la realidad social y aceptan que las cosas se hacen así "porque es la manera de hacerlas" (Scott, 1987). De esta perspectiva depende también la dinámica interna y el funcionamiento del sector, donde se busca fidelizar a los trabajadores y trabajadoras, y marcar la diferencia en el concepto que se tiene sobre los call center, crear una misma definición de ese tipo de trabajo, tener prácticas amigables, lograr un ambiente de trabajo diferente donde se tengan buenos espacios de trabajo y contacto con mucha gente; de otra parte, en cuanto al quehacer los chicos y chicas sí gustan del trabajo, argumentando que esa labor de operador es mucho mejor que estar detrás de una pala o vendiendo en la calle puerta a puerta.

Las instituciones sociales se convierten en parte del imaginario de los jóvenes y al mismo tiempo son creadas por él; éstas son las que dan sentido a los sujetos, reflejándose en normas, valores y lenguaje; así las instituciones no son sólo herramientas de creación, sino formadoras de subjetividades.

Para Castoriadis las instituciones se imponen, sólo en algunos casos, mediante la cohesión y las sanciones; los sujetos reproducen allí sus discursos y prácticas y tienen la capacidad de leer o interpretar a la sociedad para transformarla, creando nuevos sentidos y símbolos para comprender el entorno. En esta misma línea, Baeza (2000) muestra cómo el sentido permite crear subjetividades, las cuales se reflejan en discursos, en pensamientos y en la acción social.

Es entonces que los imaginarios nacen de la construcción colectiva que se manifiesta en un entorno determinado y que tienen que ver con una visión del mundo diferente; es una forma de expresión, no construida. Los seres humanos establecen diariamente relaciones en diferentes escenarios, con diversos contextos socioculturales donde el ser humano como sujeto cognoscente configura sus pensamientos, hábitos y costumbres, en un cuestionamiento continuo con su entorno; es allí, en ese espacio entre el sujeto y el objeto, donde se construyen los imaginarios, en conjunción con el otro.

\section{Resultados}

Para Borges (1998, p. 180), (...) los individuos construyen el significado del trabajo en su proceso de socialización, cuando se apropian de contenidos referentes a las concepciones formales del trabajo, a la estructura social de las organizaciones y a los aspectos socioeconómicos de las ocupaciones y del ramo de actividad.

Para comprender el sentido que dan los sujetos jóvenes al trabajo hay que partir de tres dimensiones por las que está integrado 
este concepto: 1. El significado del trabajo; 2. La centralidad del trabajo, y 3. Las normas societales.

En primer lugar está el significado que dan los jóvenes y las jóvenes al trabajo; es allí donde se exploran las definiciones que este grupo poblacional da a la categoría y también se exponen las razones por las cuales los sujetos jóvenes se incorporan al mundo laboral. Seguido se encuentra la centralidad del trabajo; esta dimensión se compone del grado de importancia que tiene el trabajo en la vida de la población joven. La tercera dimensión son las normas societales; en ellas se encuentran los deberes y derechos de los empleados y empleadas, e indaga en qué medida las personas jóvenes están informadas sobre dichas categorías. Y por último está la dimensión de los valores laborales, donde se alojan las características que son propias del trabajo y que son importantes para el día a día de los jóvenes y las jóvenes, mejorando su calidad de vida laboral y el ambiente de trabajo.

De las definiciones dadas al trabajo se puede observar dos variables que son los principales factores de motivación, y son: suplir sus necesidades económicas y crecer como personas. Los sujetos jóvenes que laboran en los call center ven el trabajo como un medio para poder demostrar su utilidad como personas: “... Es algo personal, el deseo de hacer algo, de aprender cosas nuevas, de superarte" [E, 42], una actividad que contribuye al desarrollo del entorno: “... A mí me gusta sentir que estoy haciendo algo productivo y que eso aporta a alguien..." [E, 23]; un lugar de expansión que construye identidades y donde los individuos jóvenes a su vez validan y crean espacios: "Por la necesidad de ser autosuficiente y poder ayudar en mi casa, en los gastos del hogar, y poder pagarme mis propios estudios universitarios" [E, 12].

Sin embargo, cabe resaltar que esta categoría es diversa y compleja, y que está influenciada por muchas variables.

En la presente investigación encontré que actualmente, los sujetos jóvenes están muy satisfechos con el trabajo que desempeñan: “... me siento muy a gusto con mi trabajo, yo antes trabajaba en vigilancia y me aburrí por el trasnocho, mientras que acá es muy sencillo... el horario me permite compartir con mi familia, así puedo manejar mi tiempo, los jefes no nos molestan y depende de mí si quiero vender o no" [E, 3]. Así mismo, se evidencian discursos como: “... al trabajo hay que dedicarle tiempo, porque es el segundo hogar, alli uno aporta un esfuerzo y de ese esfuerzo obtiene un ingreso de acuerdo a lo que haga" [E, 36].

La segunda dimensión tiene que ver con la importancia que tiene el trabajo en la vida de los jóvenes; aquí se evidencian principalmente dos posiciones: la primera es la importancia absoluta, relacionada con la importancia del trabajo en la vida cotidiana, donde lo más relevante es el factor económico, es decir, el trabajo como medio de subsistencia, relacionado con el deber, el deber de cumplir, el deber que muchas veces pasa a ser una obligación: "... porque si no trabajo no me visto y no como" [E, 41].

Los jóvenes buscan con su trabajo no solo cumplir con el deber e intentar sobrevivir, sino también construir relaciones sociales, ya que la especificidad de cada trabajo no proviene de las características del objeto, ni de las actividades mismas ni del tipo de producto, sino de la articulación de este proceso de producir determinadas relaciones sociales amplias, con relaciones económicas, de poder, de interés, de influencia y culturales (De la Garza-Toledo, 2000); esto conlleva a que cada sujeto tenga una postura que a su vez está siendo alterada por su interpretación, en la que entran a confluir elementos tanto internos como externos del individuo y su entorno.

De tal forma, como parte de esta importancia absoluta, aparece el trabajo como desarrollo personal y profesional, visto como una experiencia de aprendizaje; aquí la categoría es un elemento dignificante en sus vidas, que otorga identidad personal, donde se crece como persona y se adquieren nuevas experiencias: "... yo era una persona muy tímida, y la experiencia que he tenido en el call ha sido muy plácida, siento que gracias a este trabajo me desenvuelvo mejor con las personas y me hago entender de los demás" [E, 12]. Los chicos y chicas, en cuanto al quehacer, sí gustan de su trabajo: “... este trabajo es mucho mejor 
que estar detrás de una pala o vendiendo en la calle puerta a puerta" [E, 17].

Autores como Schlemenson (2002) postulan el trabajo como un dador de identidad y estructurador de la vida social y privada de las personas. Para los jóvenes y las jóvenes, el trabajo es la manera de alcanzar los sueños; este es un imaginario que está asociado a la importancia que cada uno le atribuye a trabajar según su experiencia de vida. Así mismo, es un aspecto valioso que incluye su compromiso con sigo mismo: "... de igual forma es una obligación que disfruto hacer, me entretengo y me pagan por algo que me divierte" [E, 41].

Autoras como Morin (2001) señalan que las principales razones que motivan a las personas a trabajar son: actualizar sus potenciales; adquirir seguridad y ser autónomas; relacionarse con otros y tener sentimientos de pertenencia; prestar un servicio y hacer su contribución a la sociedad; y tener un sentido. "... me motiva aportar un granito de arena así sea pequeño para ayudar a otros, aquí solucionamos problemas de otras personas y creo que eso es valioso" [E, 33]. De acuerdo con Morin (2001, p. 9), el sentido es fuertemente influenciado por la propia organización del trabajo, pues ésta "(...) debe ofrecer a los trabajadores la posibilidad de realizar algo que tenga sentido, de practicar y desarrollar sus competencias, de desarrollar sus juicios y su libre albedrío, de conocer la evolución de sus desempeños y de ajustarse". "... para mí el trabajo es un modo de vida, un modo de salir adelante, un modo de sostenimiento. El trabajo significa mucho porque yo vivo solo y tengo que pagarme todo, significa más del 70\% de mi vida" [E, 41].

Y por el último, la importancia absoluta del trabajo como medio para adquirir independencia para tener los propios ingresos. Desde esta perspectiva, me percaté de que la población joven ve el trabajo como una ganancia, como un método para obtener dinero, prestigio, para satisfacer deseos; es una manera de alcanzar un objetivo: “... el trabajo es un puente, hay dos momentos: el momento en el que tú quieres algo y el momento en que lo tienes. El trabajo es un puente que estableces entre esas dos partes, una vez lo tienes llegas al otro lado" $[E, 3]$. Esta es una muestra de que el trabajo es un elemento para adquirir independencia, construir identidad; el trabajo los hace alguien en la sociedad, les brinda status.

Igualmente está la importancia relativa. Ésta da cuenta de la importancia del trabajo con respecto a otras aéreas de la vida de los individuos jóvenes, como la familia, la educación y las actividades de ocio. A esta postura, en algunos de los sujetos entrevistados observé que el trabajo es necesario, pero no es algo esencial, así como lo es la familia: “... para mí la familia es lo más importante, el trabajo me ayuda a conseguir algunas cosas, pero es algo que está en un segundo plano" [E, 8]; “... es obvio que tenemos que trabajar para conseguir las cosas que necesitamos para vivir como la comida, la ropa etc., pero la familia está por encima de cualquier cosa y si tengo que dejar mi trabajo por mi familia lo haría" [E,12]. “... mi familia y la educación son lo más importante, porque si me quiero superar y sacarlos adelante debo trabajar y pagarme el estudio para tener un mejor trabajo" [E, 27].

La tercera dimensión tiene que ver con las normas societales, y allí son consideradas tres aéreas fundamentales: 1) el deber en el trabajo; 2) los derechos del trabajador o trabajadora; $y$ 3) el sentido de trabajar en Manizales.

En cuanto al deber en el trabajo, los jóvenes y las jóvenes son conscientes de los requisitos, normas y parámetros que deben cumplir: “...mi deber es ponerle empeño, hacer las cosas bien" $[E, 22]$. Igualmente, los líderes y lideresas cumplen un rol fundamental, ya que son quienes se encargan de fomentar un ambiente laboral saludable para la gente joven: “... aquí nuestros líderes nos ayudan a ver el lado positivo de la empresa, nos enseñan a quererla y a valorarla, ellos se encargan de que uno tenga sentido de pertenencia y eso nos hace querer y valorar todo lo que hacemos" [E, 13].

En cuanto a los derechos del sujeto trabajador, aquí se encuentran inmersos todos los elementos importantes para los individuos jóvenes en su vida laboral, destacando las relaciones basadas en el respeto, en el cumplimiento de las prestaciones de ley, en el reconocimiento por las labores realizadas y en el ambiente de crecimiento y desarrollo. A lo anterior se observa que muchas personas 
jóvenes aseguran que el sentido de trabajo en los call center es que es un empleo en el que se les permite tomar decisiones, manejar el tiempo y aplicar sus conocimientos; afirman que es un ambiente propicio para el dialogo social y para la participación en asuntos laborales, que hay espacios para hablar, escuchar e integrarse, $y$ donde se realizan reuniones para hablar sobre el trabajo y exponer ideas (Castro \& Soto, 2012; Cardona et al., 2013). “... acá tenemos la oportunidad de proponer actividades respecto al trabajo, se tienen en cuenta nuestras opiniones y también cuando tenemos quejas o reclamos nos escuchan y miran que se puede hacer para solucionarnos el problema" [E, 35].

Respecto al sentido de trabajar en Manizales, los sujetos jóvenes entrevistados en la investigación arrojaron significados valiosos sobre el hecho de trabajar en la ciudad de Manizales. En los jóvenes y las jóvenes de estratos bajos de la ciudad, los call center se han convertido en una salvación para las familias que no tienen la oportunidad de brindar una buena educación a sus hijos e hijas, lo que hace que su hogar incida en las oportunidades laborales en sectores de baja productividad. El imaginario que se crea en los hijos e hijas es que trabajar en los call center es la mejor opción que tienen para lograr sacar a sus familias de la pobreza. La mayoría de los trabajadores y trabajadoras han tenido su primera experiencia de trabajo en un call center $\mathrm{y}$, por ende, podrían ser menos objetivos para valorar su empleo "... esta es mi primera experiencia laboral, necesito el empleo para pagar el semestre y tener una bici mejor y hasta ahora se acomoda a lo que necesito" [E, 13]. Su imaginario está enfocado en que Manizales es una ciudad de oportunidades, y al no tener la suficiente experiencia laboral y vivir en una condición económica difícil las oportunidades de empleo en este sector son bastante apreciadas; "(...) el 66\% de los más jóvenes reconocen que no tendrían las mismas posibilidades en comparación con las que les brindan los call center" (Castro \& Soto, 2012, p. 21). “... yo he estado buscando en muchas partes, pero como no tengo experiencia este fue el único que me resultó" [E, 17].

De la necesidad depende que las personas jóvenes quieran o no quedarse en el call center; en muchos casos el trabajo se toma como un escampadero, cuando están en vacaciones de la universidad o necesitan dinero rápido, pero igualmente hay un importante número de jóvenes que lo ven como proyecto de vida: “... las personas creen que trabajar acá es un estancamiento, pero de verdad si usted se pone a ver esto le da la oportunidad a muchas personas que tienen la necesidad de sostener una familia o tienen la iniciativa de salir adelante" [E,4].

Debo resaltar que los jóvenes y las jóvenes construyen sus identidades laborales de acuerdo con las oportunidades que se les ofrece, ya sea en su barrio, con la familia, con sus amigos y amigas, entre otros; de esta manera dan sentido a su trabajo a partir de las diferentes experiencias vividas. La calidad y el acceso a la educación hacen que el sector sea una buena estrategia de enganche laboral para los individuos jóvenes con pocas competencias laborales.

De esta manera, se observa que a pesar de tantas diferencias entre los y las jóvenes en relación a la categoría del trabajo, el sentido y el significado de éste tiene en común que es producido por sujetos a partir de sus experiencias concretas de la realidad. Es por esto que la categoría del trabajo es una construcción elaborada en conjunto, un imaginario colectivo que surge en determinado contexto histórico, económico y social.

\section{Consideraciones Metodológicas}

Metodológicamente abordé este desde una perspectiva cualitativa a través de un diseño hermenéutico, ya que éste responde por los significados y sentidos que se configuran a partir de los imaginarios colectivos, que pueden ser identificados en los comportamientos de los sujetos jóvenes. El estudio lo hice mediante el diseño y aplicación de 50 entrevistas a profundidad, a jóvenes con 18 a 28 años de edad, de estratos socioeconómicos uno y dos que laboran en call centers de Manizales.

Para la unidad de análisis trabajé en cinco organizaciones del sector Telecomunicaciones de la ciudad de Manizales (5 Call Centers: Emergia, Digitex, Global Corp, Colombia 365 y Fullimp). La muestra la tomé en contacto 
directo con la organización, donde elegí jóvenes de estratos uno y dos de la ciudad de Manizales, con edades entre 18 a 28 años, y apliqué 10 entrevistas en cada una de las organizaciones.

En cuanto a los instrumentos, en un primer momento y para lograr escudriñar dicho imaginario, realicé entrevistas individuales a profundidad, con las que buscaba identificar en los discursos de cada joven los significados sobre el trabajo y conocer sus expresiones individuales, teniendo presente que los discursos pueden variar según el momento histórico social por el que vive cada quien.

Para identificar la dependencia solicité un análisis a cargo de un equipo de expertos integrado por investigadores e investigadoras de la Universidad de Manizales, quienes realizaron una revisión al estudio hecho a las transcripciones de entrevistas y a la forma en que éstas fueron codificadas, para evidenciar la consistencia de los resultados con las opiniones de los individuos entrevistados.

Finalmente adelanté un proceso de transcripción de las entrevistas, con el fin de clasificar las opiniones de los sujetos entrevistados en nuevas categorías; hice un análisis de contenido de los relatos y narraciones producidas por los jóvenes y las jóvenes en un grupo de discusión, donde el principal interés fue validar las percepciones, mediante un espacio de apertura en el que ellos y ellas pudieron dar su concepción sobre el trabajo, generándose un sistema grupal que permitió la construcción de significados en colectivo.

Para identificar la credibilidad del estudio hice una triangulación de información y una transcripción a profundidad de las opiniones de los individuos entrevistados, en la cual encontré coherente el discurso entre los diversos actores, lo que acreditó la veracidad de la información recopilada y me generó confianza en la misma.

\section{Conclusiones}

Hay dos aspectos esenciales que orientan mis reflexiones finales: en primer lugar, había plantado indagar por el imaginario de las personas jóvenes trabajadoras en los call center, que a simple vista parecía precario; pero realmente en los hallazgos logré evidenciar que la gente joven no lo percibe así. En este sentido, es entendible su percepción positiva, pues son jóvenes que viven en condiciones de vulnerabilidad socioeconómica (estratos 1 y 2) y educativa, jóvenes que por las características de sus microsociedades, no tienen acceso a un trabajo formal y legal que les permita subsistir dignamente, pues no están formados y no cuentan con recursos para hacerlo. De allí que quienes han logrado salir de ese círculo vicioso de la falta de acceso -pocas oportunidades de desarrollo-, es decir, los sujetos jóvenes que trabajan en este tipo de organizaciones, perciban como dignas estas condiciones laborales, pues ellos mismos consideran que “... trabajar alli les ha permitido mejor desarrollo que sus pares de la comunidad... mejor acceso al sistema de seguridad social para ellos y para sus familias"[E.3], entre otros aspectos que van desde tener recursos propios para poder acceder al sistema educativo y pagarlo ellos mismos, hasta mejorar las condiciones de vida familiar, como lo es contar con el cubrimiento al sistema de salud para ellos y sus familias o cubrir necesidades básicas de alimentación y vestido. Esto sugiere que en una comunidad donde hay unas necesidades básicas insatisfechas, este tipo de oportunidad de acceso al sistema laboral, les permite a sus miembros satisfacerlas, además les facilita proyectarse a futuro desde los procesos de formación que pueden emprender, les cambia su visión de futuro y, en la mayoría de los casos, este tipo de empresas les sirve como plataforma para su búsqueda de desarrollo, y les abre la mente sobre las oportunidades que hay en el medio no solo para subsistir sino para desarrollarse.

Desde esa lógica, es claro que para estas personas jóvenes, está en primer lugar satisfacer sus necesidades básicas insatisfechas antes que contar con buenas condiciones laborales, las cuales, para otro tipo de población que ha superado esa barrera de necesidades, serían propias de un tipo de trabajo precario. Lo anterior permite concluir que en esta población hay un sentido distinto frente al trabajo. Las personas han cambiado el sentido de su vida y las proyecciones de sus vidas empiezan a ser modificadas por la misma realidad social y económica en la que se desenvuelven. Hoy 
en día, los jóvenes y las jóvenes tienen la capacidad de reinventarse, de adaptarse bien a los cambios; al no tener responsabilidades, pueden cambiar fácilmente de empleo. Sin embargo, hay en ellos desinterés por tener su propio negocio.

Lo anterior ha generado una percepción diferente del sentido del trabajo, y ello obliga a que los mismos sistemas organizacionales tengan que pensar en medidas e indicadores distintos para determinar su orientación del trabajo y, por ende, sus condiciones de calidad de vida laboral, pues cada generación tiene sus características y encuentra su propio camino. Ahora hay nuevas formas de entender el trabajo, nuevas formas de sobrevivir económicamente, nuevas formas de trabajo que son comunes para la gente joven. No necesariamente hay una insatisfacción laboral, más bien lo que se debe resaltar es que no hay una insatisfacción en cuanto a la calidad de vida; las mismas personas jóvenes afirman que hay unas condiciones que están generando una apreciación positiva frente a su trabajo.

Las nuevas prácticas que están asumiendo los jóvenes y las jóvenes frente a laflexibilización laboral que se da en el mundo del trabajo, han hecho que ellos y ellas sean sujetos más dúctiles en cuanto a las características que eso conlleva; dicha desregulación del trabajo, donde se modifica la producción, las condiciones laborales y los procesos de administración de su personal -tales como el tipo de contrato y los horarios- es para ellos un atributo positivo del trabajo. Si bien esta generación de jóvenes no creció con el vínculo societal radical que generó alguna vez el trabajo, actualmente están satisfechos con este tipo de vinculación y se han acomodado a él, de tal manera que ni siquiera la población joven se imagina en un empleo por más de un año. Su misma condición de sujetos jóvenes dinámicos y cambiantes hace que vivan el día a día sin preocuparse por dónde estarán en un mañana, teniendo muy claro que están en una generación que ya no podrá acceder a una pensión; lo anterior es consecuencia del escaso empleo formal, resaltando también que la mayoría de los individuos jóvenes cotizantes lo hace con un ingreso que no supera los dos salarios mínimos, es decir, menos de \$1’232.000 pesos mensuales, lo que aleja a esta población de tener una mesada al momento de llegar a su edad de jubilación (País, 2014).

Este conjunto de personas está creando su propio mundo, enfrentando lo instituido con lo instituyente, donde cada quien interpreta ese mundo construyendo una realidad según sus visiones y necesidades, donde a pesar de los estigmas que tiene este sector, ellos y ellas ven algo completamente diferente lleno de características positivas, y ven un trabajo decente como cualquier otro.

Dichos individuos jóvenes no piensan que sus condiciones socioeconómicas influyan en su tipo de empleo, lo que es relevante a la hora de pensar en su satisfacción laboral: “... mis condiciones socioeconómicas no tienen nada que ver con el trabajo que tengo, creo que uno tiene que estar donde está la plata; si el día de mañana no me va bien me voy para otra parte" [E, 7]; "Por lo cual todo lo que cuestione o transforme ese sistema de interpretación es vivido, por la sociedad o el individuo, como un peligro frente a su propia identidad" (Castoriadis, 2009, p. 69); es ese momento por el que está transitando el individuo joven, el que interpreta y construye su realidad.

Es importante señalar que a pesar de las exigencias y el desgaste físico, que significa trabajar, estudiar y tener una familia, existe una alta valoración por compatibilizar ambas actividades, sobre todo porque las personas jóvenes se sienten autorrealizadas. En ese sentido, se refuerza la idea de que en términos ideales, los estudiantes y las estudiantes no quieren dejar de trabajar, sino que anhelan la existencia de oportunidades adecuadas que les permitan desarrollar ambas actividades. Se puede apreciar que la mayoría de los individuos jóvenes que trabaja no realiza jornadas laborales extensas, característica que hace ver su empleo desde una mirada positiva. En cuanto a la percepción que tienen de ser jóvenes trabajadores y trabajadoras, es una noción positiva, pues aseguran ser buenos trabajadores, con características como la puntualidad, cumplimiento de normas y horarios, la responsabilidad, el compromiso organizacional y valores esenciales como el respeto hacia sus superiores y sus compañeros 
y compañeras. Así mismo, consideran que cumplen adecuadamente con sus funciones, como tener una buena comunicación, trabajo en equipo, y cooperación, elementos que reflejan su buen desempeño en la organización.

Por último, se identifica un discurso colectivo en los jóvenes que trabajan y estudian, donde el esfuerzo individual y la realización de sus proyectos personales son el motor para rendir en ambas actividades. Trabajar les permite abrirse a nuevas experiencias, que los estudios superiores no otorgan, y conocer nuevas formas de socializar que les permitirán prepararse para la vida adulta. Como iniciativas para lograr tener un empleo mejor, se refieren a combinar el trabajo con el estudio, pues señalan que este empleo es una buena herramienta para ir pagando la carrera y así lograr salir adelante. “... igual es bueno tener esa experiencia de trabajar y estudiar, porque el mundo del estudiante no es lo mismo que el mundo del trabajador; en el trabajo uno va conociendo gente, si uno ya tiene experiencia, ya se maneja en el mundo del trabajo, uno puede acceder más fácilmente a las cosas que uno planeó cuando estaba estudiando" [E, 10].

Finalmente, cabe proponer futuras líneas de investigación que se desprenden de este estudio, como la necesidad de abordar el tema desde otras perspectivas metodológicas que permitan dar explicaciones acerca de la aceptación acrítica de los jóvenes y las jóvenes sobre las características del trabajo actual y su aporte a la construcción de nuevas prácticas laborales, al igual que nuevas identidades de los individuos jóvenes; igualmente, podría estudiarse el fenómeno del trabajo desde otras perspectivas teóricas que permitan dar cuenta de las consideraciones, por ejemplo, psicológicas, económicas y sociales a las que se enfrentan los sujetos jóvenes trabajadores en el mercado laboral actual en el país, entre otros.

\section{Lista de referencias}

Baeza, M. A. (2000). Los caminos invisibles de la realidad social. Ensayo de la sociología profunda sobre los imaginarios sociales. Santiago de Chile: RIL.
Blanch, J. M. (2011). La psicología del trabajo ante la crisis del empleo. Barcelona: Universidad Autónoma de Barcelona.

Borges, L. O. (1998). Os pressupostos dos estudos do significado do trabalho na psicologia social: no caminho do existencialismo. Vivência, 12 (2), pp. 87105.

Calderón, G. (2005). Aprender a Investigar investigando. Los errores más frecuentes en el proceso investigativo y como evitarlos. Manizales: Universidad Nacional de Colombia sede Manizales.

Cardona, A. (dir.) (2016, Abril 1). Noticiero Caracol [Audio de programa radial]. Caracol Radio. Recuperado de: http://caracol.com.co/emisora/2016/04/01/ manizales/1459510932_021449.html

Cardona, M.; Soto, I.; Serna, M.; Castro, E.; Celis, M. \& Botero, A. (2013). Sector $B P O$, estudio de perfiles ocupacionales del sector Business Process Outsourcing en la ciudad de Manizales. Manizales: Centro Editorial Universidad de Manizales.

Castoriadis, C.(1989). La institución imaginaria de la sociedad. Buenos Aires: Tusquets.

Castoriadis, C. (2009). Los dominios del hombre. Las encrucijadas del laberinto. Barcelona: Gedisa.

Castro, E. \& Soto, I. (2012). Calidad del empleo y condiciones de trabajo en los call center en la ciudad de Manizales. Manizales: Editorial Universidad Nacional de Colombia sede Manizales.

Consejo Privado de Competitividad (2010). Informe Nacional de Competitividad 20142015. Bogotá, D. C.: Consejo Privado de Competitividad.

Dane (2015). Gran Encuesta Integrada de Hogares. Bogotá D. C.: Dane.

De la Garza-Toledo, E. (2000). La flexibilidad del trabajo en América Latina. En E. De la Garza-Toledo (2003). Tratado Latinoamericano de Sociología del Trabajo, (pp. 148-178). México, D. F.: Colegio de México, Facultad Latinoamericana de Ciencias Sociales, Universidad Autónoma Metropolitana, Fondo de Cultura Económica. 
Martínez, D. (2006). Democracia y trabajo decente en América Latina. Lima: Oficina Internacional del Trabajo.

Morin, E. M. (2001). Os sentidos do trabalho. Revista de Administração de Empresas, 41 (3), pp. 8-19. Doi: 10.1590/S003475902001000300002

Neffa, J. C. (2003). El trabajo humano. Contribuciones al estudio de un valor que permanece. Buenos Aires: Ceil-Piette, Conicet, Lumen Hvmanitas.

Organización Internacional del Trabajo (2004). Un buen comienzo: trabajo decente para los jóvenes. Ginebra: OIT.

Organización Internacional del Trabajo (2012). Reducir el déficit de trabajo decente: un desafio global. Ginebra: OIT.

Pfeffer, J. (1987). Organizaciones y Teoría de las Organizaciones. Buenos Aires: El Ateneo.

Portafolio (2015, junio 11). Desempleo juvenil bajó 1,1\% en el país. Recuperado de: http:// www.portafolio.co/economia/desempleojuvenil-2015-colombia.

Rivera-González, J. G. (2011). Tres miradas a la experiencia de la exclusión en las juventudes en América Latina. Revista Latinoamericana de Ciencias Sociales, Niñez y Juventud, 9 (1), pp. 331-346.

Rojas, C. A. (2011). Una revisión de la producción de conocimiento sobre transiciones y trayectorias laborales juveniles. Revista de Antropología y Sociología Virajes, (13), pp. 309-334.

Schlemenson, A. (2002). La estrategia del talento. Buenos Aires: Paidós.

Scott, R. (1987). TheAdolescenseoí Institutional Theory. Administrative Science Quaterly, 32 (4), pp. 493-511.

Somavía, J. (2000). Reducir el déficit de trabajo decente: un desafio global. Ginebra: OIT.

Valenzuela, J. M. (1998). Identidades juveniles. En C. H. Cubides, M. C. Laverde-Toscano, C. E. Valderrama (eds.) Viviendo a toda: jóvenes, territorios culturales y nuevas sensibilidades, (pp. 38-45). Bogotá, D. C.: Paidós, Universidad Central. 